\title{
Ankaferd Blood Stopper for controlling gastrointestinal bleeding due to distinct benign lesions refractory to conventional antihemorrhagic measures
}

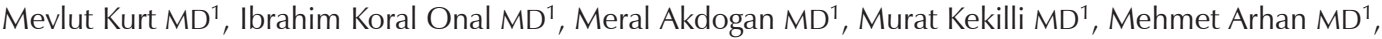 \\ Abdurrahim Sayilir MD ${ }^{1}$, Erkin Oztas MD¹, Ibrahim Celalettin Haznedaroglu MD²
}

\begin{abstract}
M Kurt, IK Onal, M Akdogan, et al. Ankaferd Blood Stopper for controlling gastrointestinal bleeding due to distinct benign lesions refractory to conventional antihemorrhagic measures. Can J Gastroenterol 2010;24(6):380-384.
\end{abstract}

OBJECTIVE: To assess the hemostatic efficacy of the Ankaferd Blood Stopper (ABS, Ankaferd Health Products Ltd, Turkey) hemostatic agent for controlling gastrointestinal bleeding associated with various benign lesions refractory to conventional antihemorrhagic measures. METHODS: The records of all patients who underwent upper and lower endoscopy procedures at the Turkiye Yuksek Ihtisas Teaching and Research Hospital (Ankara, Turkey) between April 2008 and June 2009 were reviewed. Patients in whom ABS was used as a primary or adjuvant hemostatic agent were included in the study. Rates of bleeding control and postprocedural complications were documented.

RESULTS: Hemostasis with no immediate complications was achieved in all patients within seconds of endoscopic application of ABS.

CONCLUSIONS: ABS may have a role as a primary treatment or as an adjuvant to conventional modalities used to control gastrointestinal bleeding. Prospective controlled studies are needed to help establish its efficacy and, perhaps, offer a comparison with conventional hemostatic interventions.

Key Words: Ankaferd Blood Stopper; Bleeding; Dieulafoy's lesion; Mallory-Weiss tear; Polypectomy; Radiation colitis

A nkaferd Blood Stopper (ABS, Ankaferd Health Products Ltd, Turkey) is a unique medicinal plant extract that has historically been used as a hemostatic agent in Turkish traditional medicine (1). As a medicinal product, ABS has been approved for the management of external hemorrhage and dental surgery bleeding in Turkey, based on safety and efficacy reports supporting its sterility and nontoxicity. ABS is currently licensed as a hemostatic agent in Turkey and Bosnia-Herzegovina. ABS is available in several forms - as a tampon, spray and ampules. It is a completely herbal product and $100 \mathrm{~mL}$ of ABS comprises a standardized mixture of plants, including $5 \mathrm{mg}$ Thymus vulgaris (dried grass extract), $9 \mathrm{mg}$ Glycyrrhiza glabra (dried leaf extract), $8 \mathrm{mg}$ Vitis vinifera (dried leaf extract), $7 \mathrm{mg}$ Alpinia officinarum (dried leaf extract) and $6 \mathrm{mg}$ Urtica dioica (dried root extract). The basic mechanism

\section{L'Ankaferd Blood Stopper pour contrôler les saignements gastro-intestinaux causés par des lésions bénignes distinctes réfractaires aux mesures antihémorragiques classiques}

\begin{abstract}
OBJECTIF : Évaluer l'efficacité hémostatique de l'Ankaferd Blood Stopper (ABS, Ankaferd Health Products Ltd, Turquie), un médicament hémostatique, pour contrôler les saignements gastro-intestinaux associés à diverses lésions bénignes réfractaires aux mesures antihémorragiques classiques.

MÉTHODOLOGIE : Les chercheurs ont examiné le dossier de tous les patients qui ont subi des interventions gastroduodénales ou digestives basses à l'hôpital de recherche et d'enseignement Turkiye Yuksek Ihtisas (Ankara, Turquie) entre avril 2008 et juin 2009. Les patients qui avaient reçu de l'ABS comme médicament hémostatique primaire ou adjuvant étaient inclus dans l'étude. Ils ont documenté les taux de contrôle du saignement et de complications après l'intervention.

RÉSULTATS : Tous les patients ont profité d'une hémostasie sans complications immédiates dans les secondes suivant l'application endoscopique de l'ABS.

CONCLUSIONS : L'ABS pourrait jouer un rôle dans le traitement primaire ou adjuvant des modalités classiques utilisées pour contrôler les saignements gastro-intestinaux. Des études prospectives contrôlées s'imposent pour contribuer à en déterminer l'efficacité et, peut-être, à le comparer aux interventions hémostatiques classiques.
\end{abstract}

of action of ABS is the formation of an encapsulated protein network that provides focal attachment points for very rapid (less than $1 \mathrm{~s}$ ) vital erythrocyte aggregation, which is known as the hemostatic 'ABS web'. ABS-induced protein network formation with blood cells, particularly erythrocytes, covers the primary and secondary hemostatic system without disturbing individual coagulation factors (1).

The in vivo hemostatic effect of ABS was evaluated in rats pretreated with acetylsalicylic acid (ASA) or enoxaparin, as well as in a swine model $(2,3)$. There is accumulating evidence of ABS efficacy in gastrointestinal (GI) system bleeding (4-8). Analysis of a recent case series (8) revealed that neoplastic GI bleeding could be successfully managed via topical application of $\mathrm{ABS}$, whereas experience with benign conditions is limited (4-7). The aim of the present retrospective, observational study

${ }^{1}$ Department of Gastroenterology, Turkiye Yuksek Ihtisas Teaching and Research Hospital; ${ }^{2}$ Department of Hematology, Hacettepe University Medical Faculty, Ankara, Turkey

Correspondence: Dr Mevlut Kurt, Department of Gastroenterology, Turkiye Yuksek Ihtisas Teaching and Research Hospital,

Kizilay Sok. No:2, 06100 Sihhiye, Ankara, Turkey. Telephone 90-505-2762812,fax 90-312-3124120, e-mail dr.mevlutkurt@gmail.com

Received for publication August 26, 2009. Accepted October 25, 2009 
TABLE 1

Diagnoses, demographics, associated diseases, Ankaferd Blood Stopper* (ABS) doses, and other procedures and drugs used to control bleeding in the present series

\begin{tabular}{|c|c|c|c|c|c|c|}
\hline Diagnosis & Patient & Age/sex & Procedure (polyps removed, n) & ABS dose, $\mathrm{mL}$ & Drug & Associated disease \\
\hline Mallory-Weiss tear & 1 & $79 / \mathrm{M}$ & Hemoclips, adrenaline & 7 & Warfarin & $\begin{array}{l}\text { Coronary artery disease, dilated } \\
\text { cardiomyopathy }\end{array}$ \\
\hline Esophageal lesion & 2 & $85 / \mathrm{M}$ & & 40 & & Sepsis \\
\hline \multirow[t]{4}{*}{ Gastric lesion } & 3 & $77 / \mathrm{M}$ & Biopsy & 6 & ASA & Diabetes mellitus \\
\hline & 4 & $76 / F$ & Biopsy & 10 & & Hypertension, chronic hepatitis C \\
\hline & 5 & $83 / \mathrm{M}$ & Biopsy & 9 & & Alzheimer's disease, chronic hepatitis C \\
\hline & 6 & $76 / F$ & Biopsy & 15 & Warfarin & Coronary artery disease \\
\hline Polyp & 7 & $58 / F$ & Polypectomy (7) & 14 & & Hypertension \\
\hline \multirow[t]{5}{*}{ Gastric } & 8 & $61 / \mathrm{M}$ & Polypectomy (2) & 6 & Warfarin & Hypertension, venous insufficiency \\
\hline & 9 & $72 / F$ & Polypectomy (3) & 18 & & Hypertension, diabetes mellitus \\
\hline & 10 & $75 / F$ & Polypectomy(1) & 5 & ASA & Hypertension \\
\hline & 11 & $72 / \mathrm{M}$ & Polypectomy (2) & 5 & ASA & \\
\hline & 12 & $45 / F$ & $\begin{array}{l}\text { Polypectomy (1), hemoclips, } \\
\text { adrenaline }\end{array}$ & 14 & & \\
\hline \multirow[t]{2}{*}{ Duodenal } & 13 & $22 / F$ & Polypectomy (2) & 9 & & Peutz-Jeghers syndrome \\
\hline & 14 & $39 / F$ & Polypectomy (1) & 10 & & Chronic liver disease \\
\hline Colon & 15 & $58 / \mathrm{M}$ & Polypectomy (1) & 3 & & Chronic hepatitis B \\
\hline \multirow[t]{2}{*}{ Rectal } & 16 & $67 / F$ & Polypectomy (2) & 10 & & Rheumatoid arthritis \\
\hline & 17 & $23 / \mathrm{M}$ & $\begin{array}{r}\text { Submucosal dissection, } \\
\text { hemoclips, adrenaline }\end{array}$ & 40 & & \\
\hline \multirow[t]{2}{*}{ Dieulafoy's lesion } & 18 & $44 / \mathrm{M}$ & Hemoclips & 10 & & \\
\hline & 19 & $58 / \mathrm{M}$ & Hemoclips, adrenaline & 84 & & \\
\hline \multirow[t]{3}{*}{ Radiation colitis } & 20 & $71 / \mathrm{M}$ & Argon plasma coagulation & $17+25$ & ASA & $\begin{array}{l}\text { Coronary artery disease, hypertension, } \\
\text { prostate cancer }\end{array}$ \\
\hline & 21 & $70 / \mathrm{M}$ & Argon plasma coagulation & 15 & & Prostate cancer \\
\hline & 22 & $79 / \mathrm{M}$ & Argon plasma coagulation & 15 & ASA & $\begin{array}{l}\text { Diabetes mellitus, hypertension, } \\
\text { prostate cancer }\end{array}$ \\
\hline \multirow{3}{*}{$\begin{array}{l}\text { Gastric antral vascular } \\
\text { ectasia }\end{array}$} & 23 & $62 / F$ & Argon plasma coagulation & 15 & & Diabetes mellitus, hypertension, COPD \\
\hline & 24 & $75 / F$ & Argon plasma coagulation & 20 & & Chronic hepatitis B \\
\hline & 25 & $66 / F$ & Hemoclips & 10 & & $\begin{array}{l}\text { Cryptogenic cirrhosis, diabetes mellitus, } \\
\text { hypertension }\end{array}$ \\
\hline Congestive gastropathy & 26 & $83 / \mathrm{M}$ & - & 10 & ASA, warfarin & Right-sided heart failure \\
\hline
\end{tabular}

*Ankaferd Health Products Ltd, Turkey. ASA Acetylsalicylic acid; COPD Chronic obstructive pulmonary disease; F Female; M Male

was to assess the hemostatic efficacy of ABS for controlling GI bleeding associated with various benign lesions refractory to conventional antihemorrhagic measures.

\section{METHODS}

\section{Patients}

The records of 10,711 patients who underwent upper and lower endoscopy procedures at Turkiye Yuksek Ihtisas Teaching and Research Hospital (Ankara, Turkey) between April 2008 and June 2009 were reviewed. Patients in whom ABS was used as either a primary or adjuvant hemostatic agent were included in the present study. After the exclusion of subjects with malignancies, data on 26 patients were collected. Patient age, sex, medical history and associated disease, concomitant medication, endoscopic diagnosis and interventional endoscopic procedures performed were recorded. For all patients, written informed consent regarding the off-label use of ABS as a means of attaining hemostasis was obtained. In all cases, the choice of hemostatic agent was left to the attending senior endoscopist's discretion based on whether ABS was used solely or as an adjuvant to other interventions such as hemoclips, heater probe, argon plasma coagulation or sclerotherapy. Patient records were also reviewed for any evidence of rebleeding after the procedure.
In all patients, ABS was applied topically at varying doses. Olympus XQ20, 1 T20 (Olympus, Japan) and Pentax EG2940 (Pentax, USA) diagnostic endoscopes were used for the topical application of ABS by a disposable washing pipe (PW-205L, Olympus, Japan). One $50 \mathrm{~mL}$ vial of ABS (patent number 2007-0-114485) was provided by Ankaferd Health Products Ltd (Istanbul, Turkey).

\section{RESULTS}

Controlling of bleeding was achieved in all instances for which ABS was used as either the sole method of hemostasis or as an adjuvant to other modalities. The details of the patients and procedures performed are summarized in Table 1.

Of particular interest is the case history of patient 1 who experienced hematemesis while in the coronary intensive care unit. His pre-endoscopy hemoglobin level was $68 \mathrm{~g} / \mathrm{L}$. He was on chronic warfarin anticoagulation threrapy and had a preprocedural international normalized ratio of 3.1. During the bedside procedure, bright red blood was observed in the esophagus and stomach. An actively bleeding Mallory-Weiss tear was seen on the $Z$ line. Application of topical ABS enabled accurate localization of an oozing lesion for which four hemoclips and sclerotherapy with $6 \mathrm{~mL}$ of a 1:10,000 dilution of 


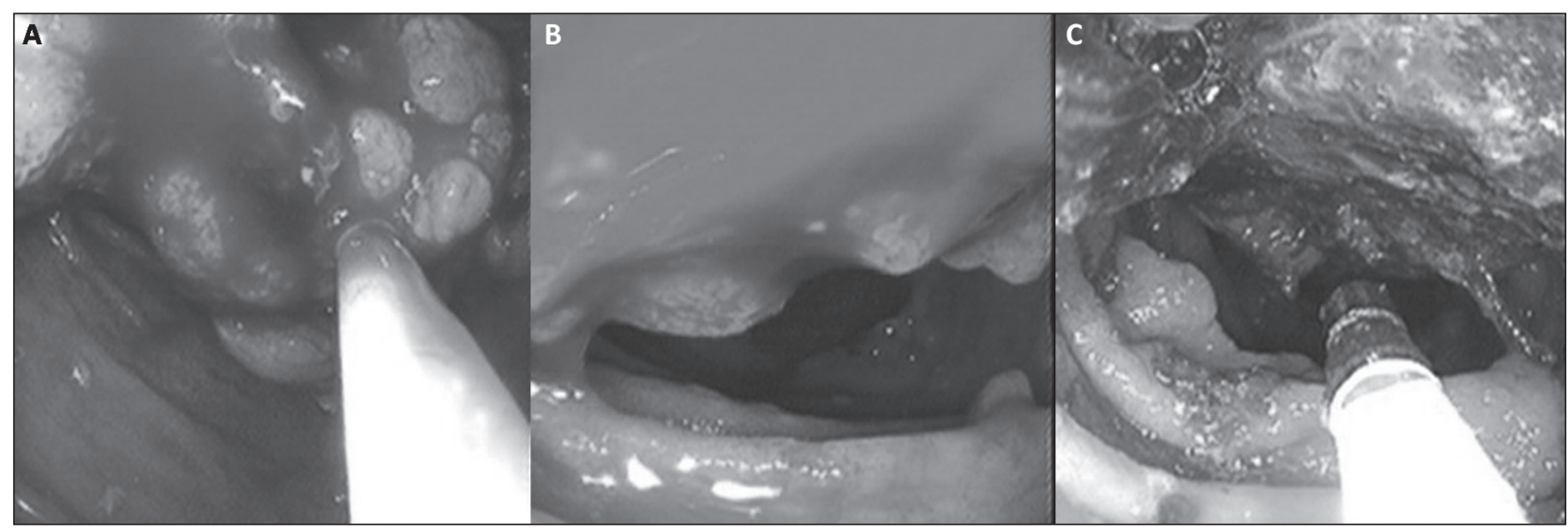

Figure 1) Patient 13. A Endoscopic view of a $3 \mathrm{~cm}$ pedunculated polyp in the second portion of the duodenum. B The polyp was removed by snare cautery and significant bleeding was observed. C Hemostasis was achieved after application of Ankaferd Blood Stopper (Ankaferd Health Products, Turkey) solution

adrenaline were applied. On repeat endoscopy one day later, the clips remained in place, with no signs of active bleeding. His hemoglobin level 11 days later was $102 \mathrm{~g} / \mathrm{L}$.

Patient 2 had undergone total gastrectomy surgery in May 2009. He experienced postoperative multiorgan failure, and while in the general surgery intensive care unit, he developed hematemesis. His hemoglobin level was $55 \mathrm{~g} / \mathrm{L}$. Upper endoscopy on this particular intubated and mechanically ventilated patient revealed actively bleeding esophageal ulcers attributed to a previously inserted nasogastric tube. ABS was topically applied to the bleeding area and hemostasis was successfully achieved.

Patient 13 had several episodes of intussusceptions caused by polyps and emergent surgical partial enterectomies. The polyps that were previously excised were histopathologically hamartomatous. Upper gastrointestinal endoscopy was performed under general anesthesia. Multiple gastric and duodenal millimetric polyps were excised with biopsy forceps and snare polypectomy. A pedunculated polyp approximately $3 \mathrm{~cm}$ in diameter was seen in the second portion of the duodenum (Figure 1A). During the piecemeal polypectomy, significant bleeding was observed (Figure 1B). Nine milliliters of ABS was topically applied to the bleeding area. The bleeding was successfully stopped immediately (Figure 1C), and the polypectomy procedure was completed with no complications. The patient had no signs or symptoms associated with GI hemorrhage during the one-month period after the polypectomy session.

Patients 18 and 19 were also prominent in that they both presented with melena, with upper endoscopy revealing actively bleeding Dieulafoy's lesions. Application of endoclips and sclerotherapy with hypertonic adrenaline solution failed to control bleeding in both cases. Subsequent endoscopic application of ABS resulted in immediate cessation of bleeding in patient 18; however, patient 19 continued to bleed and was referred for surgical intervention.

Patients 20 to 22 had proven radiation colitis, which was primarily managed with argon plasma coagulation. Adjuvant use of ABS in these patients resulted in more sustained control of bleeding.

\section{DISCUSSION}

Our experience with ABS in 26 patients with GI bleeding from esophageal, gastroduodenal and colorectal mucosa showed that ABS may have a role as a primary treatment or as an adjuvant to conventional modalities. This hemostatic agent seems promising because of its efficacy, particularly in patients with hemorrhagic diathesis, which occurred in nine patients with defective hemostasis secondary to chronic ASA or warfarin use.

Mallory-Weiss syndrome (MWS) was determined to be the etiology of upper GI bleeding in 3\% to 10\% of cases in a recent series (9). Most of the time, hemorrhaging in MWS stops spontaneously and patients can benefit from conservative medical management. However, some patients, especially those with stigmata of active bleeding and unstable vital signs at admission and/or associated comorbid diseases, may require a hemostatic procedure (10). Hemoclip placement, adrenaline injection and band ligation are safe and effective methods for the treatment of MWS-associated bleeding $(11,12)$. In our patient with MWS, a combined endoscopic treatment was not effective, possibly because of warfarin use, and the bleeding could be stopped only after the topical administration of ABS. Our other patient with severe esophagitis accompanied by esophageal ulcers responded well to ABS. ABS was previously used in a patient with solitary rectal ulcer syndrome (6); it may have a role in coating ulcerated surfaces. ABS has shown in vitro antimicrobial activity on clinical isolates of both Gram-positive and Gram-negative bacteria (13). This might have contributed to the healing effect of ABS in our final patient who also had sepsis. In our series, there were no patients with gastroduodenal ulcer bleeding, but ABS may influence the healing rate of ulcers, especially if future studies demonstrate anti-Helicobacter pylori activity.

ABS was successfully used in four patients with various gastroduodenal lesions (Figure 2A and B). Cold biopsy of the gastric mucosa is useful in many gastroduodenal disorders. Antral biopsies are performed with increasing frequency to confirm $H$ pylori infection and to determine the type and extent of gastritis. GI bleeding after gastric cold biopsy is a rare but potential complication (14) and it may be observed more frequently in endoscopic biopsies of the gastric remnant after 

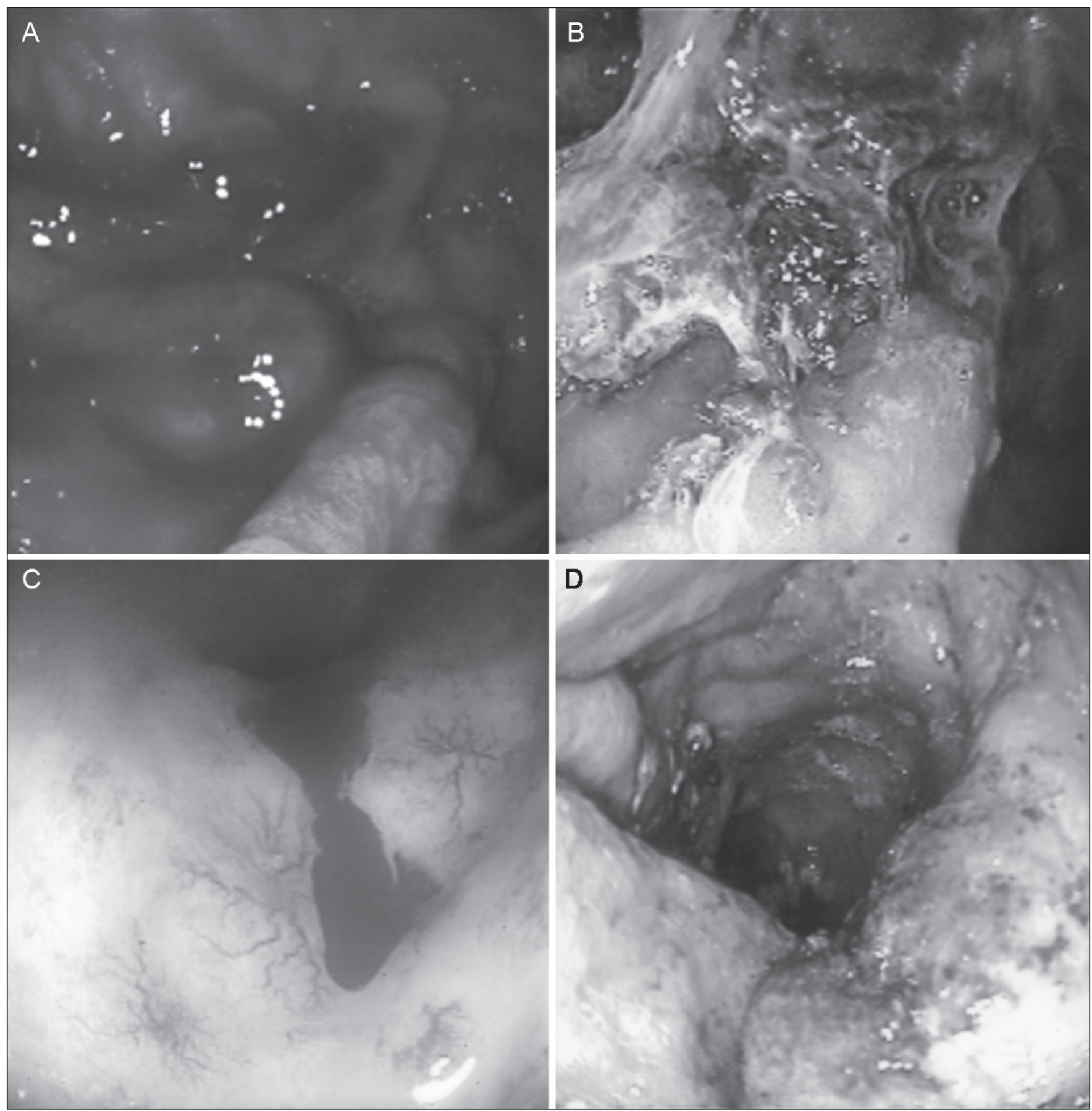

Figure 2) Endoscopic application of Ankaferd Blood Stopper (Ankaferd Health Products Ltd, Turkey) solution for gastric bleeding after endoscopic biopsies in patient 3 (A,B). Application of Ankaferd Blood Stopper solution as an effective adjunctive hemostatic agent for the management of active bleeding secondary to radiation colitis in patient 20 (C,D)

ulcer surgery (15). Use of antihemostatic agents may contribute to bleeding. Recently, low-dose ASA was shown to prolong bleeding after gastric biopsy in a group of patients (16). ABS may be prophylactically administered to the gastric mucosa following biopsy in patients having gastric remnants, comorbid conditions associated with hemostatic deficiency (eg, chronic renal and liver failure) and antihemostatic drug use (eg, ASA, warfarin and clopidogrel). In our three patients with gastric antral vascular ectasia (GAVE), ABS improved the efficacy of argon plasma coagulation. Although the etiology of GAVE is poorly understood, histopathology results demonstrated distinct abnormalities limited to the mucosa and lamina propria, including superficial fibromuscular hyperplasia with capillary ectasia (17). ABS may lead to microvascular thrombosis and decrease bleeding in these patients; however, controlled trials are needed to support the use of ABS in GAVE because another hemostatic agent, tranexamic acid, did not demonstrate significant efficacy (18).

We used ABS in several patients with gastroduodenal and colorectal polyps. Postpolypectomy bleeding is a major 
complication of endoscopic polypectomy, with incidences ranging from $0.3 \%$ to $6.1 \%(19,20)$. Several factors such as type of current used, polyp size and histology, stalk diameter, patient characteristics and use of anticlotting drugs, have been associated with the increased incidence of bleeding following polypectomy (21). We did not observe postpolypectomy bleeding in our cohort of patients that included one with chronic liver disease and three who were undergoing antihemostatic drug therapy. Although we observed that ABS improved the efficacy of argon photocoagulation in radiation colitis (Figures $2 \mathrm{C}$ and D), controlled studies are needed in this area.

The efficacy of ABS depends on direct contact with the bleeding surface. The amount of ABS used is dependent on the extent of bleeding. ABS is applied at increasing doses until hemostasis is achieved, up to a maximum dose of $84 \mathrm{~mL}$. Although spray catheters are available in our hospital and would have been ideal, we used the PW-205L disposable wash pipe for the topical application of ABS solution to completely cover the bleeding surface. ABS must remain in contact with the bleeding surface. Removal of the resulting ABS web usually results in rebleeding. Our experience in two patients with Dieulafoy lesions led us to conclude that topical application of ABS is of no benefit for spurting arterial bleeding when used on its own due to the forceful nature of the bleeding, although its use as an adjuvant to other modalities (eg, endoclips or heater probe) deserves consideration. However, ABS may play a significant role in controlling oozing such as from angiodysplasia, tumoral and postpolypectomy bleeding, and radiation colitis.

\section{REFERENCES}

1. Goker H, Haznedaroglu IC, Ercetin S, et al. Haemostatic actions of the folkloric medicinal plant extract, Ankaferd Blood Stopper. J Int Med Res 2008;36:163-70.

2. Kosar A, Cipil HS, Kaya A, et al. The efficacy of Ankaferd Blood Stopper in antithrombotic drug-induced primary and secondary hemostatic abnormalities of a rat-bleeding model. Blood Coagul Fibrinolysis 2009;20:185-90.

3. Bilgili H, Kosar A, Kurt M, et al. Hemostatic efficacy of Ankaferd Blood Stopper in a swine bleeding model. Med Princ Pract 2009; 18:165-9.

4. Kurt M, Oztas E, Kuran S, Onal IK, Kekilli M, Haznedaroglu IC. Tandem oral, rectal, and nasal administrations of Ankaferd Blood Stopper to control profuse bleeding leading to hemodynamic instability. Am J Emerg Med 2009;27:631.

5. Kurt M, Kacar S, Onal IK, Akdogan M, Haznedaroglu IC. Ankaferd Blood Stopper as an effective adjunctive hemostatic agent for the management of life-threatening arterial bleeding of the digestive tract. Endoscopy 2008;40(Suppl 2):E262.

6. Ibis M, Kurt M, Onal IK, Haznedaroglu IC. Successful management of bleeding due to solitary rectal ulcer via topical application of Ankaferd Blood Stopper. J Altern Complement Med 2008;14:1073-4.

7. Kurt M, Disibeyaz S, Akdogan M, Sasmaz N, Aksu S, Haznedaroglu IC. Endoscopic application of Ankaferd Blood Stopper as a novel experimental treatment modality for upper gastrointestinal bleeding: A case report. Am J Gastroenterol 2008;103:2156-8.

8. Kurt M, Akdogan M, Onal IK, et al. Endoscopic topical application of Ankaferd Blood Stopper for neoplastic gastrointestinal bleeding: A retrospective analysis. Dig Liver Dis 2010;42:196-9.

9. Di Fiore F, Lecleire S, Merle V, et al. Changes in characteristics and outcome of acute upper gastrointestinal haemorrhage: A comparison of epidemiology and practices between 1996 and 2000 in a multicentre French study. Eur J Gastroenterol Hepatol 2005; 17:641-7.
No adverse systemic effect was detected after the administration of this particular medicinal product. During the local administration of ABS, a local macroscopic, dirty-white discolouration was observed, and the hemostatic web formed by the rapid formation of the network, together with the colour changes, may cause problems in detecting bleeding lesions. Therefore, the hemostatic agent must be applied after precisely locating the source of oozing blood. The discolouration was observed to disappear when control endoscopy was performed. Direct injection of ABS is not recommended for obvious reasons. There is always a risk of intravascular leakage after topical application, which may be an issue in GI bleeding in which mucosal integrity could be severely compromised. However, experience with the product for dental bleeding has proven to be quite safe, with no reports of embolic events to date.

\section{CONCLUSION}

Our series in the control of GI bleeding associated with various benign lesions refractory to conventional antihemorrhagic measures suggest that ABS can be effectively used in various situations of GI bleeding. Further controlled studies are needed to establish ABS as a novel, safe and effective treatment option for the control of GI bleeding.

CONFLICTS OF INTEREST: The authors have no conflicts of interest to declare.

10. Bharucha AE, Gostout CJ, Balm RK. Clinical and endoscopic risk factors in the Mallory-Weiss syndrome. Am J Gastroenterol 1997;92:805-8.

11. Park CH, Min SW, Sohn YH, et al. A prospective, randomized trial of endoscopic band ligation vs epinephrine injection for actively bleeding Mallory-Weiss syndrome. Gastrointest Endosc 2004;60:22-7.

12. Yamaguchi Y, Yamato T, Katsumi N, et al. Endoscopic hemoclipping for upper GI bleeding due to Mallory-Weiss syndrome. Gastrointest Endosc 2001;53:427-30.

13. Tasdelen Fisgin N, Tanriverdi Cayci Y, Coban AY, et al. Antimicrobial activity of plant extract Ankaferd Blood Stopper. Fitoterapia 2009;80:48-50.

14. Vu CK, Korman MG, Bejer I, Davis S. Gastrointestinal bleeding after cold biopsy. Am J Gastroenterol 1998;93:1141-3.

15. Domellöf L, Enander LK, Nilsson F. Bleeding as a complication to endoscopic biopsies from the gastric remnant after ulcer surgery. Scand J Gastroenterol 1983;18:951-4.

16. Yamamoto T, Kuyama Y, Kozuma K, Isshiki T. Low-dose aspirin prolongs bleeding after gastric biopsy in Japanese patients. Thromb Res 2008;122:722-3.

17. Jabbari M, Cherry R, Lough JO, et al. Gastric antral vascular ectasia: The watermelon stomach. Gastroenterology 1984;87:1165-70.

18. McCormick PA, Ooi H, Crosbie O. Tranexamic acid for severe bleeding GAVE in cirrhosis. Gut 1998;42:750-2.

19. Nelson DB, McQuaid KR, Bond JH, Lieberman DA, Weiss DG, Johnston TK. Procedural success and complications of large-scale screening colonoscopy. Gastrointest Endosc 2002;55:307-14.

20. Sorbi D, Norton I, Conio M, Balm R, Zinsmeister A, Gostout GJ. Postpolypectomy lower GI bleeding: Descriptive analysis. Gastrointest Endosc 2000;51:690-6.

21. Watabe H, Yamaji Y, Okamoto M, et al. Risk assessment for delayed hemorrhagic complication of colonic polypectomy: Polyp-related factors and patient-related factors. Gastrointest Endosc 2006;64:73-8. 


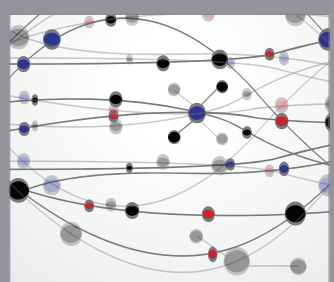

The Scientific World Journal
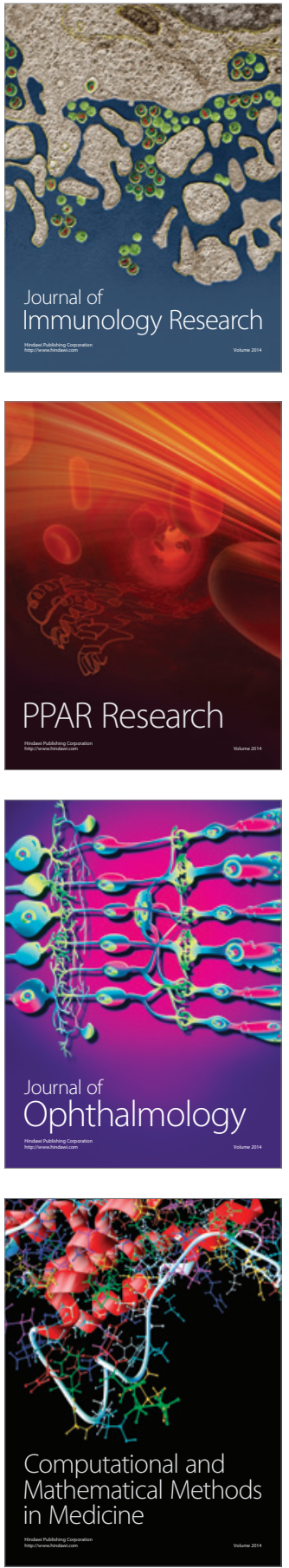

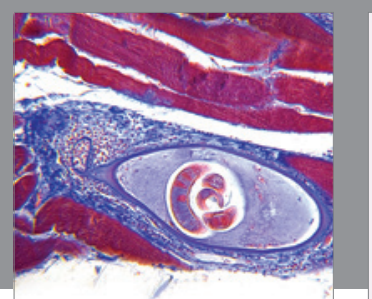

Gastroenterology Research and Practice

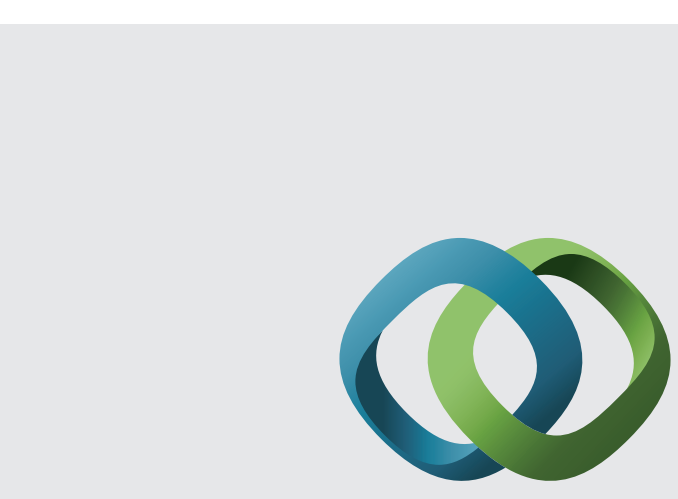

\section{Hindawi}

Submit your manuscripts at

http://www.hindawi.com
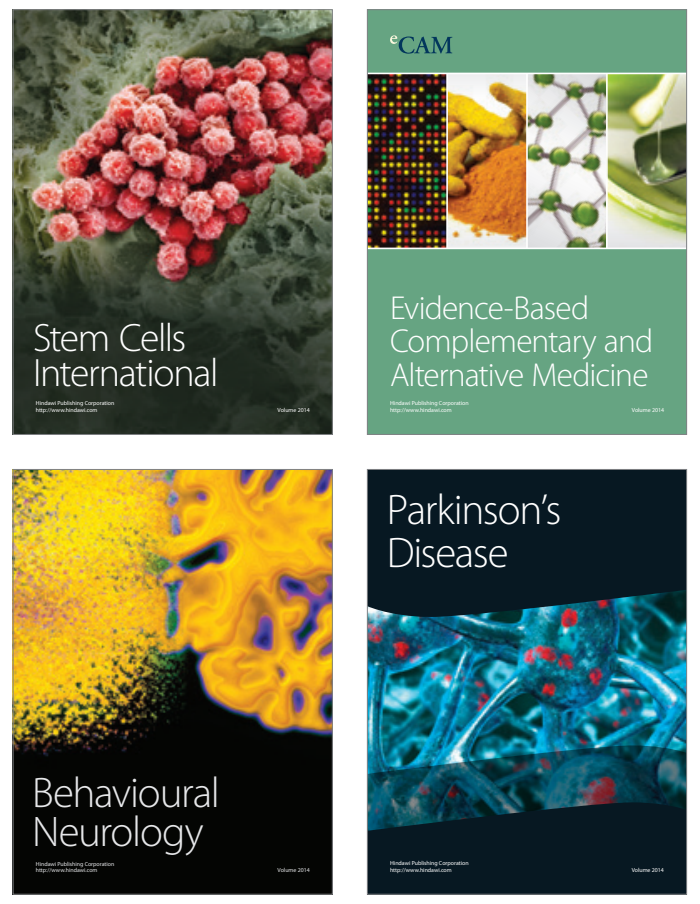
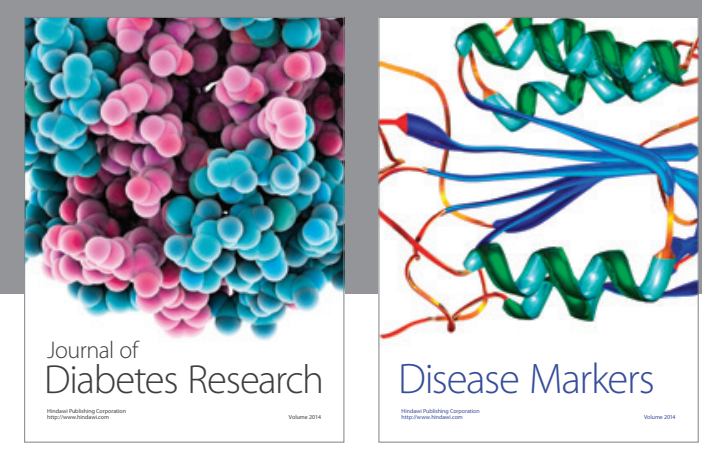

Disease Markers
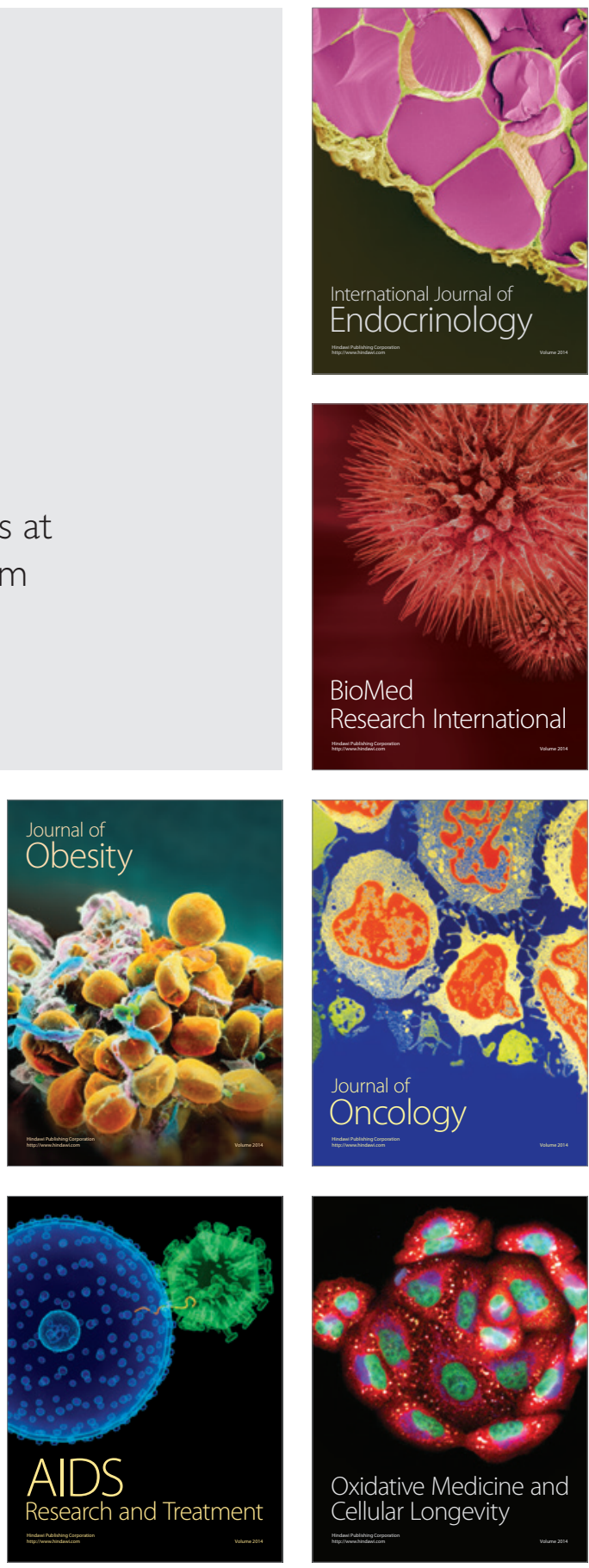